Article

\title{
Small-Scale Static Fire Tests of 3D Printing Hybrid Rocket Fuel Grains Produced from Different Materials
}

\author{
Mitchell McFarland and Elsa Antunes* \\ College of Science and Engineering, James Cook University, 1 James Cook Drive, Townsville, \\ QLD 4811, Australia \\ * Correspondence: elsa.antunes1@jcu.edu.au
}

Received: 1 March 2019; Accepted: 10 July 2019; Published: 15 July 2019

\begin{abstract}
The last decade has seen an almost exponential increase in the number of rocket launches for sounding missions or for delivering payloads into low Earth orbits. The emergence of new technologies like rapid prototyping, including 3D printing, is changing the approach to rocket motor design. This project conducted a series of small-scale static fire tests of fused deposition manufacturing hybrid rocket motors that were designed to explore the performance of a variety of commonly available fused deposition manufacturing materials. These materials included acrylonitrile butadiene styrene, acrylonitrile styrene acrylate, polylactic acid (PLA), polypropylene, polyethylene terephthalate glycol, Nylon, and AL (PLA with aluminum particles). To test the performance of small-scale fuel grains, a modular apparatus with a range of sensors fitted to it was designed and manufactured. The small-scale testing performed static burns on two fuel grains of each material with initial dimensions of $100 \mathrm{~mm}$ long and $20 \mathrm{~mm}$ in diameter with a $6 \mathrm{~mm}$ straight circular combustion port. The focus of this study was mainly on the regression rates of each material of fuel grains. Acrylonitrile styrene acrylate and Nylon showed the highest regression rates, while the polyethylene terephthalate glycol regression rates were relatively poor. Also, the acrylonitrile butadiene styrene and acrylonitrile styrene acrylate demonstrating relatively high regression rates when compared to existing hybrid fuels like hydroxyl-terminated polybutadiene.
\end{abstract}

Keywords: 3D printing; fuel grain; hybrid combustion; regression rate

\section{Introduction}

In the last decade, interest and investment in space exploration has increased dramatically. This has led to greater demand for satellites, and subsequently, more companies are investing significant resources into lowering the cost of space launches. Previously, the manufacture of a Hybrid Rocket Motor (HRM) was costly and labor-intensive, and the traditional 'cast and cure' method limited the geometry of internal combustion ports [1,2]. In an effort to overcome the manufacturing limitations of hybrid rocket fuel grains, researchers have looked to emerging technology and novel techniques to produce innovative solutions that have previously been unattainable. The most notable of these has been the impressive advancement in rapid prototyping, especially fused deposition manufacturing (FDM), commonly known as 3D printing [3]. FDM has enabled designers to incorporate complex combustion ports into HRMs and has opened up an entirely new set of materials for the fabrication thereof.

The process of the 3D printing involves the laying down of successive layers of material on top of each other until a 3D shape has been created [4]. The material is generally supplied in the form a thin strand, or filament, that is wound onto spools to be fed into a heating reservoir and extrusion nozzle assembly. The nozzle assembly is controlled by a computer numerically controlled (CNC) mechanism and has the ability to travel both horizontally and vertically. This means that the only limitations placed on the size of the object being printing is the size of the print area of the particular printer being 
used. However, some companies have already created printers that can essentially print large parts, such as a house, in a short period of time (less than a day) [3]. This is achieved by printing the part length-ways on a conveyor belt, with each new layer being added on a $45^{\circ}$ angle, allowing a full-sized hybrid rocket fuel grain to be completed in a single print. Other companies, such as Gilmour Space Technologies, have created both a proprietary printing method and material [5].

Traditionally, the materials used in 3D printing are generally polymers, such as acrylonitrile butadiene styrene (ABS), polylactic acid (PLA), acrylonitrile styrene acrylate (ASA), or polypropylene $(\mathrm{PP})$, but can include anything from metals, ceramics, food, and concrete to living stem cells [3,6,7]. More recently, the commercial market has seen a rapid increase in the number of filaments with metal particles in its composition, such as brass, copper and aluminum. Although it is possible to 3D print metallic materials [8], the filaments discussed herein have a PLA binding structure, with a fine powder of the desired metal finish added during the manufacturing process.

Favorable comparison of ABS against hydroxyl-terminated polybutadiene (HTPB) as a hybrid rocket fuel suggests that FDM has the potential to revolutionize the fabrication of hybrid rocket fuel grains, and has led a groundbreaking push for the development and enhancement of 3D-printed fuel grains at the Utah State University [9]. This study, carried out at the Utah State University, demonstrated that not only did ABS have an acceptable (although slightly reduced) performance when compared to HTPB, but that it also showed much higher burn-to-burn consistency which was attributed to the FDM process [9]. Similar work has been carried out at Purdue University and at the University of Tennessee [10,11].

The introduction of FDM into the manufacturing process of HRM fuel grains has also allowed for the creation of far more complex combustion port geometries. The traditional method of 'cast and cure,' which is used for materials such as HTPB and paraffin, requires a mold and internal tooling that can be quite complex depending on the desired geometry of the fuel grain [12]. Although recent work has been done on the use of disposable tooling structures, it is generally accepted that once the fuel mixture has cured, the internal tooling must be removed before the motor is ready for use. This has limited the complexity of the design of HRM grain ports, in so far as they must be able to allow for the removal of the tooling after the manufacturing process, generally resulting in straight ports that run the length of the motor. In contrast to this, FDM lays down each successive layer of material on top of the last, which, in components like HRM fuel grains, rarely requires the use of internal support. Even if support structure is required, this is added in the same manner as the fuel and is manufactured from water soluble material that is easily removed after manufacture [13].

Several recent studies have explored the use of rapid prototyping in the design and fabrication of HRM fuel grains. The bulk of research in this field has been carried out at the Utah State University and has centered around the exploration of the effects of a helical fuel grain on the performance of the HRM regression rate [12,14-17]. It has been shown that the helical combustion port significantly increased the regression rate when compared to straight cylindrical ports. It has been posited that this is a result of both an increase in the local skin friction, and the suppression of the radial wall blowing effect is due to the centrifugal forces introduced by the helical flow [16]. These centrifugal forces cause compression of the boundary layer, forcing the flame front closer to the fuel port wall and significantly increasing the convective heat transfer. The use of aluminum particles to increase performance of solid and HRMs has long been studied [18-20]. It has been shown that the addition of aluminum particles can increase specific impulse, volumetric heat of oxidation, and radiative heat transfer [21], as well as increase regression rates in HTBP rocket motors by up to $40 \%$ [22]. It is generally understood that this increase in regression rate is due to improvement of radiative heat flux from the diffusion flame zone to the fuel surface area via the radiating metallic particles and higher gas-phase temperature $[23,24]$.

However, it has also been demonstrated that the addition of aluminum particles does not necessarily always result in an increase in regression rates [25]. Regression rate improvement can also be a result of the release of energy during metal oxidation, but the higher temperatures required to melt the aluminum oxide layer often mean that the fuel binder is melted and burnt before the 
aluminum [21,24]. The result is that the aluminum particles are ejected from the motor without significantly contributing to the regression rate increase [26], and can form slag build-up on the nozzle wall, as well as drastically increase nozzle throat ablation [20]. A key contributing factor to the performance enhancement abilities of the added aluminum is the size of the particles. It has been shown that nanosized particles perform better than micro-sized particles, resulting in higher combustion efficiencies, better heat transfer, and reduced burn time [23].

This research project conducted a series of small-scale static fire tests of FDM HRMs that were designed and 3D-printed to explore the performance of a variety of commonly available FDM materials. These materials included ABS, ASA, PLA, PP, PETG (Polyethylene terephthalate glycol), Nylon, and AL (PLA with aluminum particles). The main objective of this research study was to analyze and compare the performance of these materials in terms of the mass flux and regression rate.

\section{Methodology}

\subsection{Material Selection}

The initial series of fuel grains tested were manufactured from commercially available ABS, ASA, PLA, AL, PETG, Nylon, and PP. ABS has been selected as it has been shown to perform as well as HTBP at lab-scale static fire tests [2,9], while ASA was selected due to its similarities to ABS. The PLA was selected as a benchmark with which to test the $\mathrm{Al}$, as there is currently no commercially available aluminum-doped ABS. PETG and Nylon were selected due to their excellent mechanical properties, which would be beneficial if they were used as a structural component of the rocket, and finally, PP was selected due to its low price and because it is a highly crystalline material. Table 1 describe the main characteristics of the seven materials tested in this study.

Table 1. Structural, thermal, and mechanical properties of test materials [27].

\begin{tabular}{ccccc}
\hline Material & Structure & $\boldsymbol{\rho} \mathbf{( g \cdot \mathbf { m } ^ { - 3 } )}$ & $\begin{array}{c}\text { Tensile Yield } \\
\text { Strength (MPa) }\end{array}$ & $\begin{array}{c}\text { Printing } \\
\text { Temperature }\left({ }^{\circ} \mathbf{C}\right)\end{array}$ \\
\hline ABS & Non-crystalline, amorphous & 1010 & 55 & $220-260$ \\
ASA & Non-crystalline, amorphous & 1000 & 40 & $220-250$ \\
PLA & Moderate degree of crystallinity & 1225 & 63 & $190-220$ \\
PLA-Al & Moderate degree of crystallinity & 1330 & 70 & $200-220$ \\
PETG & Moderate degree of crystallinity & 1230 & 50 & $230-250$ \\
Nylon & Moderate degree of crystallinity & 1150 & 55 & $220-260$ \\
PP & High degree of crystallinity & 980 & 40 & $230-260$ \\
\hline
\end{tabular}

\subsection{Design and Manufacture of Fuel Grains}

The small-scale fuel grains were designed to be $100 \mathrm{~mm}$ long and $20 \mathrm{~mm}$ in diameter with a $6 \mathrm{~mm}$ diameter combustion port. It is typical for HRM fuel grains to have high aspect ratios in order to achieve the desired oxidizer to fuel $(\mathrm{O} / \mathrm{F})$ ratios, and it was believed that this combination of port diameter and fuel grain length would provide that. A straight, circular combustion port was selected for the small-scale motor case verification testing and for the material selection testing, as this is the simplest and easiest to manufacture, as well as the simplest to evaluate. A series of ABS grains were printed using a Prusa i3 MK2 FDM 3D printer (Prusa Research s.r.o., Prague, Czech Republic) that were used to verify the operation of the test stand and small-scale motor case. Once the performance of the apparatus was confirmed, two fuel grains of each of the seven materials being tested (ABS, ASA, PLA, AL, PETG, Nylon, and PP) were 3D-printed using the printing temperature range described in Table 1. All fuel grains were designed to have the same dimensions. However, it was expected that due to the manufacturing process, some post-production machining was required for some materials. 


\subsection{Testing of Fuel Grains}

The testing regime was separated into two main rounds conducted at small-scale. Within these tests, there was an apparatus verification component and a fuel grain testing component. The first round of small-scale testing was designed to confirm the operation of the existing small motor casing and to verify the operation of the newly constructed test stand (Figure 1), sensors, and data logger. Several verification burns were conducted using circular, straight port ABS fuel grains. The purpose of these initial tests was to ensure that motor and nozzle were operating in the choked condition and that the chamber pressure was within the operating limits of the motor case and associated plumbing. These initial tests also allowed the data logger code to be tested and modified as required, and the correct operation of the sensors to be verified. The fuel grains of the seven different materials were then subjected to a single, three-second burn each. The testing regime consisted of:

- Measuring and recording the initial weight of the fuel grain

- Measuring and recording the initial weight of the oxidizer bottle

- Placing the fuel grain in the testing apparatus and subjecting it to a three-second burn

- Removing the fuel grain and measuring and recording the final weight

- Measuring and recording the final weight of the oxidizer bottle

These measurements allowed for the determination of the fuel and oxidizer and total mass flow rates, $\mathrm{O} / \mathrm{F}$ ratio, and the fuel regression rate.

To measure chamber pressure, an analogue gauge was initially mounted to a brass outlet tube plumbed to the mixing chamber at the fore of the motor case. Once the correct operation of the rocket motor was confirmed, a digital pressure transducer was used in place of the analogue gauge, allowing much more accurate measurement and recording, as well as the option to plot the pressure chamber throughout the duration of each burn. A Honeywell heavy duty, 10 BAR ratiometric pressure sensor was chosen for its robust construction and represented an excellent compromise between performance and price. Protection from over pressurization was via a 1.0 MPa pressure relief valve that was installed in-line with both the analogue gauge and pressure transducer. Temperature protection was provided via the installation of a thermocouple below the pressure measurement devices. This thermocouple provided real-time feedback on the temperatures being experienced by gauges, allowing the burn to be stopped prematurely if temperatures approached or exceeded the maximum operating temperatures of the unit.
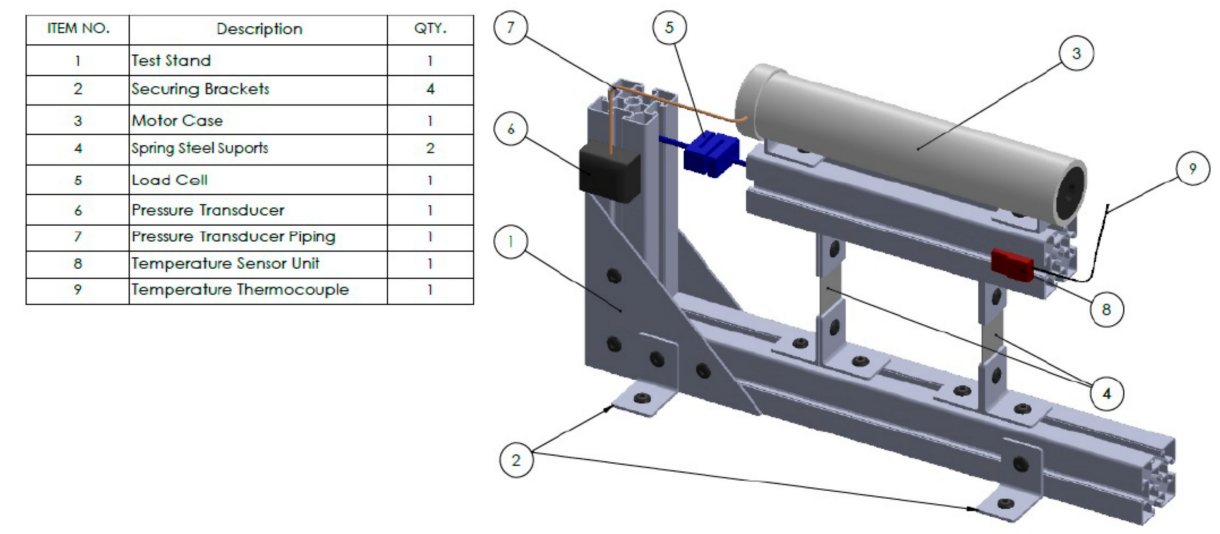

Figure 1. Schematic of the laboratory-rocket motor test stand with sensors. 


\section{Results}

\subsection{Testing}

Fuel grains were designed based on literature values and also taking in account limits of available 3D printers [28]. Preliminary tests were carried out with ABS fuel grains to analyze integrity of fuel grains and thrust. All of the experiments (preliminary and others) were carried out in triplicates.

In the initial testing, a burn of four seconds resulted in the fuel grain losing structural integrity, and subsequently, allowing its outer surface (the surface of the grain in contact with the motor casing) to begin to vaporize and contribute to the overall combustion as well. Not only is this undesirable from an operational perspective, it also renders the regression rate calculations invalid. These calculations rely on the principle that any fuel removed from the grain via combustion occurred solely in the combustion port. Without the ability to differentiate between the mass removed from the combustion and the mass removed from the outer surface, the calculations significantly over-estimate the combustion port regression rate.

Once the burning time was reduced to three seconds, the structural integrity of the fuel grain was far better preserved with combustion of fuel being limited to within the combustion port. Three further tests were then conducted with $100 \mathrm{~mm} \times 20 \mathrm{~mm}$ ABS fuel grains to ensure the repeatability of the test stand chamber pressure measurement.

The results of the thrust validation show excellent consistency across the three burns, with very similar profiles demonstrated in each run. The precise moment of motor cut-off can be seen across all three tests at the four-second mark.

The seven fuel grains 3D-printed with different materials are shown in Figure 2.

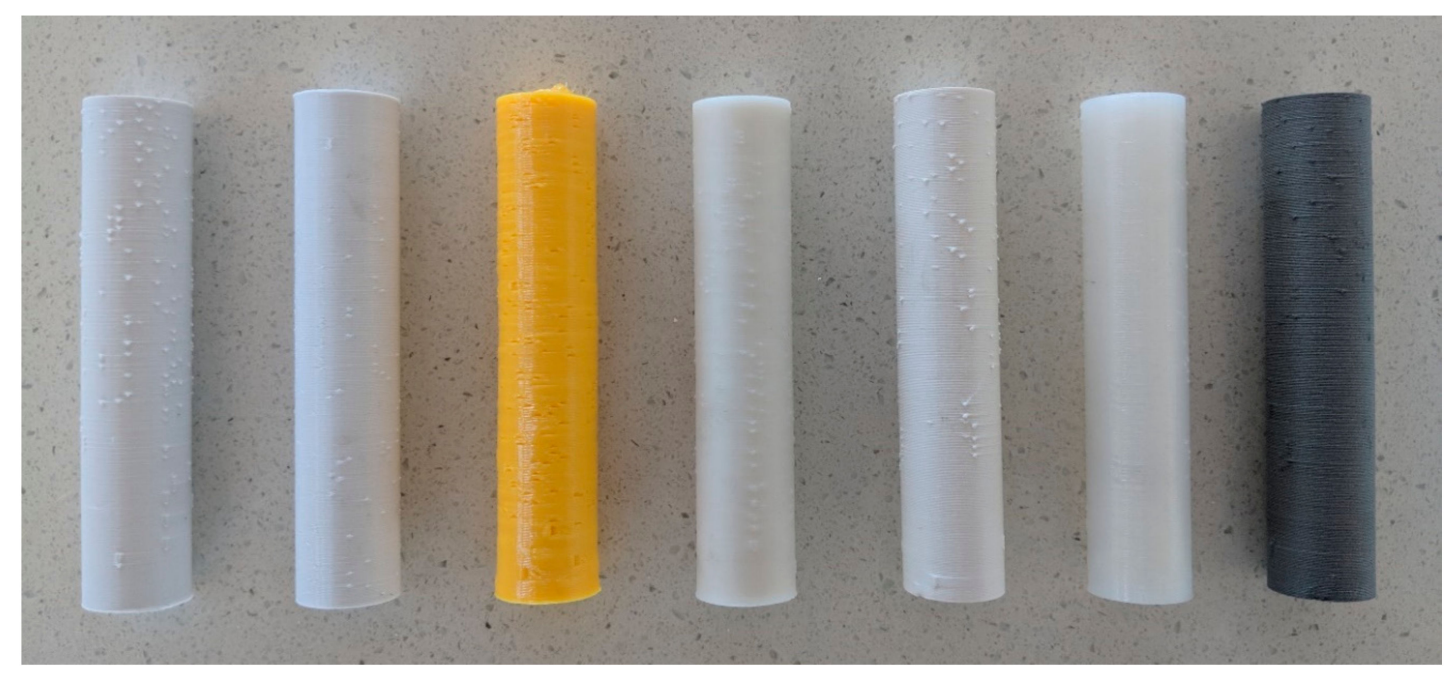

Figure 2. Small-scale fuel grains, left to right: ABS, PLA, PETG (Polyethylene terephthalate glycol), PP, ASA, Nylon, and AL (PLA with aluminum particles).

Although the majority of the fuel grains were 3D-printed ready to burn, several printing settings were modified slightly to ensure the structural integrity of the layers and to minimize any surface defects that could negatively impact the fuel grain performance. In some materials, these settings resulted in small blobs, known as "zits," on the outer surface of the print, and in some cases, extreme oozing, or "stringing," across the combustion chamber. For complex internal geometries, these settings would need to be refined to ensure completely homogeneous layers, a smooth exterior, and clean combustion port. However, the experiments were focused on material selection rather than port geometry, and as such, a straight circular port was used, meaning that the external surface and combustion port could simply be machined to the correct dimensions as required. 
Once the machining had been completed, two fuel grains for each material were subjected to a single three second burn each (Figure 3). Although all fuel grains performed reasonably well, as indicated by the size and shape of the exhaust plume exiting the nozzle, there was a noticeable difference between the better performing materials and those that did not perform well. Visual inspection of each burn suggested that the ABS and ASA performed very well, and it was also noted that the PETG burn was significantly hotter than any of the other burns. Of all the materials tested, the AL appeared to have performed extremely well, with an incredibly energetic combustion. However, inspection of the regression rate data, outlined in Section 3.2, shows that it was, in fact, one of the worst performing materials.

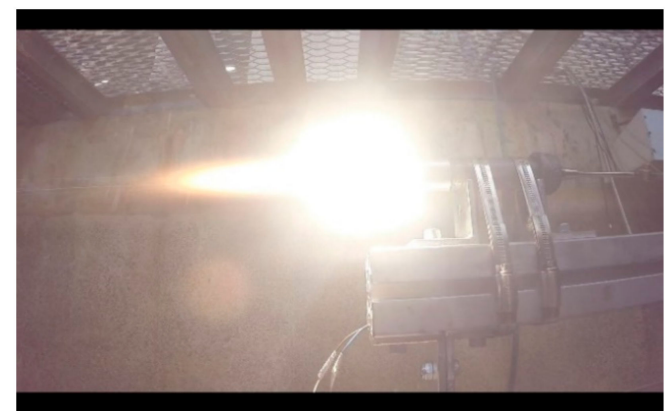

(a) ABS

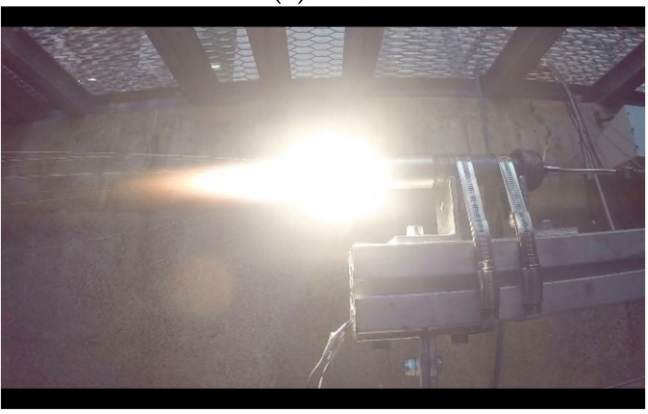

(c) PETG

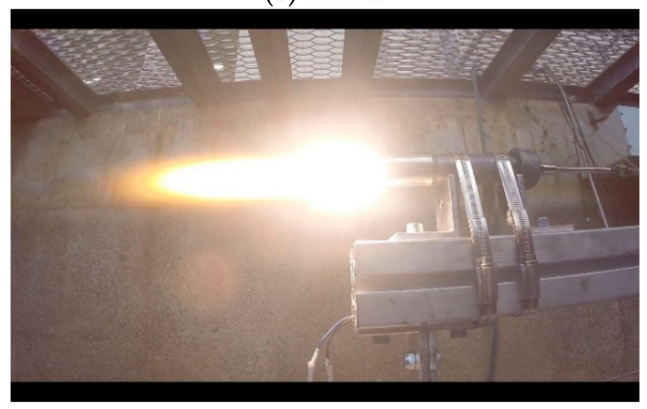

(e) ASA

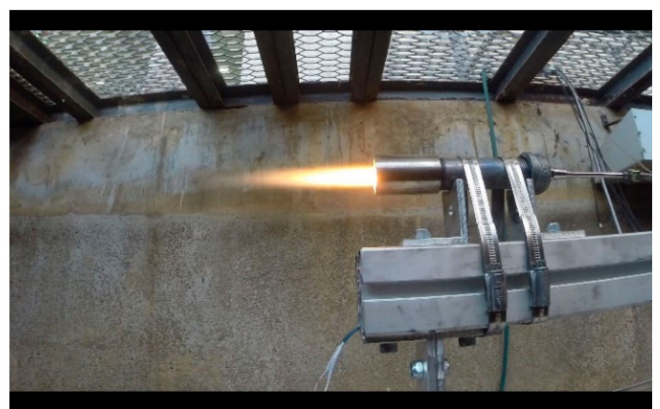

(b) PLA

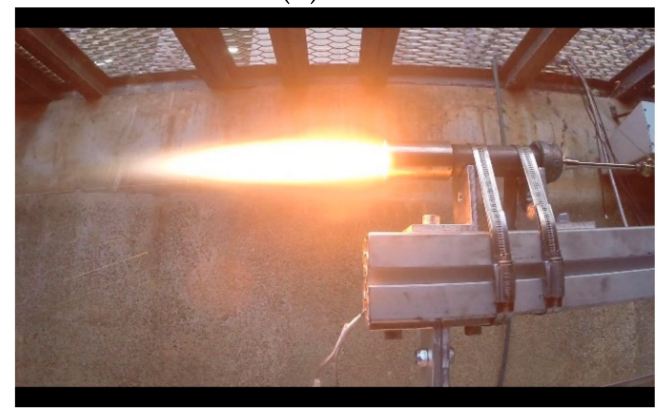

(d) PP

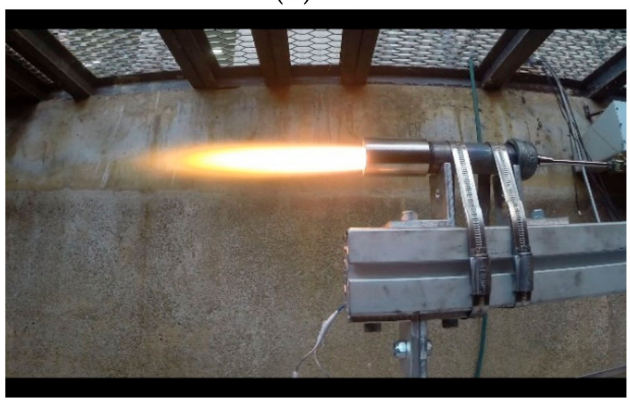

(f) Nylon

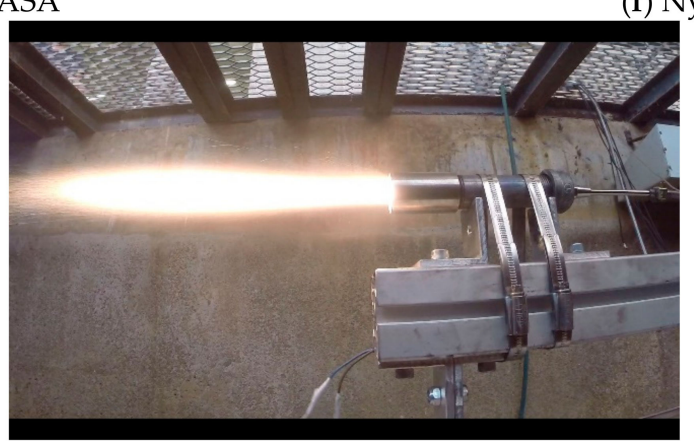

(g) $\mathrm{AL}$

Figure 3. Small-scale testing of fuel grains 3D-printed from different fused deposition manufacturing (FDM) materials. 


\subsection{Regression Rate}

The time-averaged longitudinal fuel regression rate $\overline{\dot{r}}$ for each of the fuel grains can be calculated (Equation (1)) using the mass flow of the fuel grain [17]:

$$
\overline{\dot{r}}=\frac{\dot{m}_{f u e l}}{\rho_{f u e l} \cdot 2 \cdot \pi \cdot \bar{r}_{\text {port }} \cdot L}
$$

where $\dot{m}_{f u e l}$ is the time-average mass flow rate of the fuel, $\rho_{\text {fuel }}$ is the density of the fuel, $\bar{r}_{\text {port }}$ is the mean fuel combustion chamber radius, and $L$ is the length of the fuel combustion port. $\dot{m}_{f u e l}$ can be calculated using the measured fuel mass loss $(\Delta M)$ and dividing by the burning time $\left(t_{b}\right)$. The time-averaged fuel port radius can be determined by Equation (2) [24]:

$$
\bar{r}_{\text {port }}=\sqrt{r_{0}^{2}+\frac{\Delta M}{\rho_{\text {fuel }} \cdot \pi \cdot L}}
$$

where $r_{0}$ is the initial fuel port radius. Once the time-averaged fuel port radius has been calculated, it is then possible to determine the total mass flux of the fuel grain using Equation (3):

$$
\bar{G}_{\text {total }}=\frac{\dot{m}_{\text {total }}}{A_{\text {port }}}
$$

where $\dot{m}_{\text {total }}$ is the total mass flow rate through the combustion port and $A_{\text {port }}$ is the area of the combustion port. Substituting Equation (2) into Equation (3) yields Equation (4):

$$
\bar{G}_{t o t a l}=\frac{\dot{m}_{o x}+\dot{m}_{f u e l}}{\pi \cdot\left(r_{0}^{2}+\frac{\Delta M}{\rho_{f u e l} \cdot \pi \cdot L}\right)}
$$

where $\dot{m}_{o x}$ is the mass flow rate of the oxidiser and $\dot{m}_{f u e l}$ is the mass flow rate of the fuel. Table 2 shows

\begin{tabular}{|c|c|c|c|c|c|c|}
\hline Material & $\rho\left(\mathrm{kg} \mathrm{m}^{-3}\right)$ & $\dot{m}_{o x}\left(\mathrm{~kg} \mathrm{~s}^{-1}\right)$ & $\dot{m}_{f u e l}\left(\mathrm{~kg} \mathrm{~s}^{-1}\right)$ & O/F Ratio & $\dot{m}_{\text {total }}\left(\mathrm{kg} \mathrm{s}^{-1}\right)$ & $\overline{\dot{r}}\left(\mathrm{~mm} \mathrm{~s}^{-1}\right.$ \\
\hline ABS & 1010 & 0.0100 & 0.0023 & 4.35 & 0.0123 & 1.05 \\
\hline ASA & 1000 & 0.0125 & 0.0030 & 4.17 & 0.0155 & 1.59 \\
\hline $\mathrm{AL}$ & 1330 & 0.0108 & 0.0025 & 4.32 & 0.0133 & 1.20 \\
\hline PLA & 1225 & 0.0100 & 0.0025 & 4.00 & 0.0125 & 1.23 \\
\hline PETG & 1230 & 0.0108 & 0.0035 & 3.09 & 0.0143 & 0.94 \\
\hline Nylon & 1150 & 0.0100 & 0.0027 & 3.70 & 0.0127 & 1.51 \\
\hline $\mathrm{PP}$ & 890 & 0.0100 & 0.0023 & 4.35 & 0.0123 & 1.23 \\
\hline
\end{tabular}
the average data from the small-scale testing as well as the results of time-averaged longitudinal fuel regression rate of the burn calculated using Equation (1).

Table 2. Results of the small-scale test fire of 3D-printed fuel grains.

The material with the highest average regression rate was found to be ASA, followed closely by Nylon, while PETG had the lowest average regression rate. It was observed that the fuel port radius of the ASA grain increased by the greatest amount. Despite the expected energetic combustion of the AL fuel grain, it was found to have a regression rate similar to the PLA without the addition of aluminum powder. This shows that the aluminum powder did not impact on the regression rate, perhaps due to its particle size and surface area. The regression rate of ABS fuel grain was one of the lowest of the materials tested. A similar value to ASA was expected due to their similar chemical and mechanical properties. This unexpected value can be explained by the low oxidizer mass flux for ABS. 
Inspection of the exhaust end of each fuel grain reveals similar results. Figure 4 shows the exit of the combustion port for each different material, and while it is difficult to make accurate measurements of combustion port diameters, certain observations can be made. It is clear that the PLA and AL (PLA with aluminum particles) have significantly smaller diameters than the other materials, which correlate well with the results in Table 2. Conversely, ABS and PP appear to have relatively large combustion port diameters, which was expected for ABS but surprising for the PP grain. It is worth noting at this point that the Nylon grain could not be removed from the motor case without significant damage, and as it could not be examined in this way, it was not further evaluated in this study.

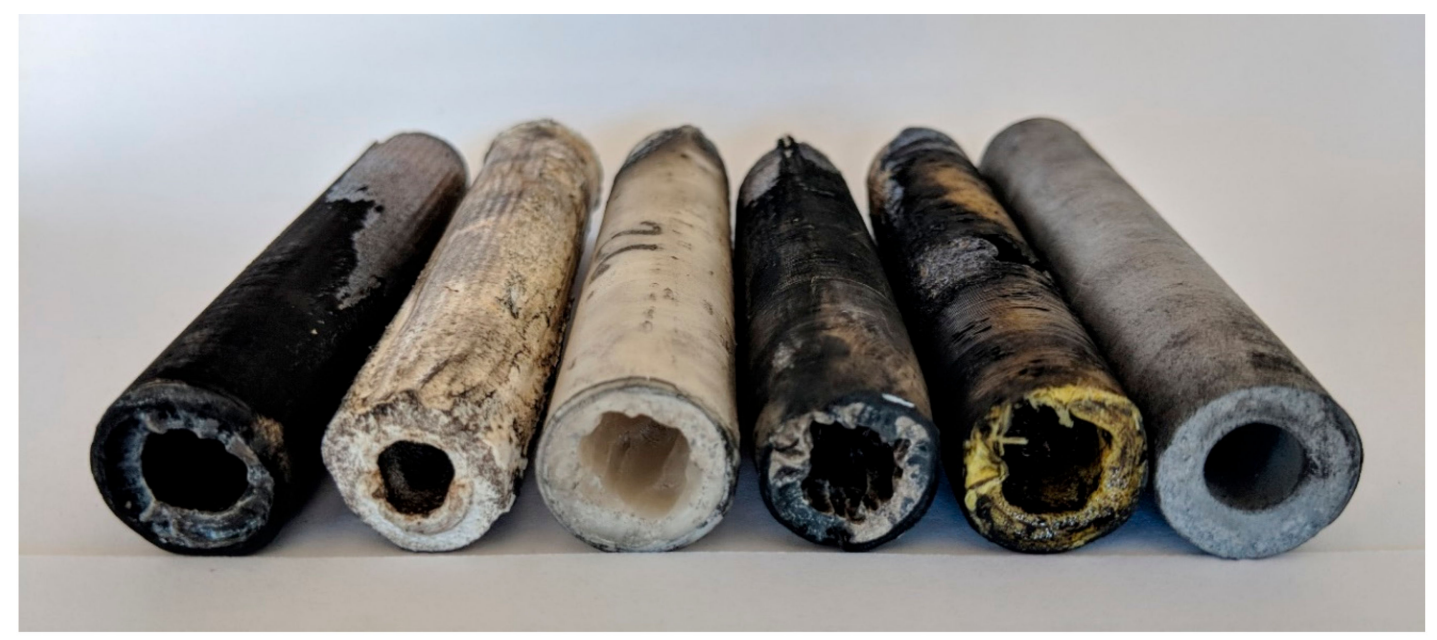

Figure 4. Combustion port comparisons, left to right: ABS, PLA, PP, ASA, PTEG, and AL.

To further validate these results, each fuel grain was cut in half longitudinally, allowing for a more comprehensive view of the ablation of the combustion chamber as seen in Figure 5. It is from this cross-sectional view that it is possible to see from where the increased regression rate for ASA occurred. Examination of the exhaust end of the combustion port of the ASA grain suggests that it may have had similar regression rates to the AL grain. However, it is clear that significant regression occurred throughout the length of the chamber, with the exhaust and inlets end of the combustion port potentially dilating post-burn. Inspection of Figure 5 also reveals that combustion within the AL fuel grain did not occur at the beginning of the combustion port. This resulted in a small section of fuel grain that was not contributing to the regression rate, yet still being taken into account for calculations involving grain weight and port length. This may have contributed somewhat to the poor performance of the AL, but not to the levels seen in this experiment.

The poor performance of the AL fuel grain is believed to be due to the size of the aluminum particles added to the base PLA. It has been shown that the optimum particle size required to significantly increase fuel regression rates is between 0.05 to $0.1 \mathrm{~mm}$ [22]. This size range represents an incredibly fine powder, with an associated cost that would be above an economically feasible option for commonly available 3D printing filaments for some conventional applications. Thus, it could be proposed that the aluminum powder did not actively improve the radiative heat flux from the flame zone to the fuel surface, nor release significant energy during metal oxidation. The latter could be largely due to the larger particle size, which would result in the particles being ejected from the motor prior to the melting of their aluminum oxide coating. Inspection of Figure $3 g$ reveals a large number of highly energized particles being ejected from the motor during the burn, which correlates well with this hypothesis. 


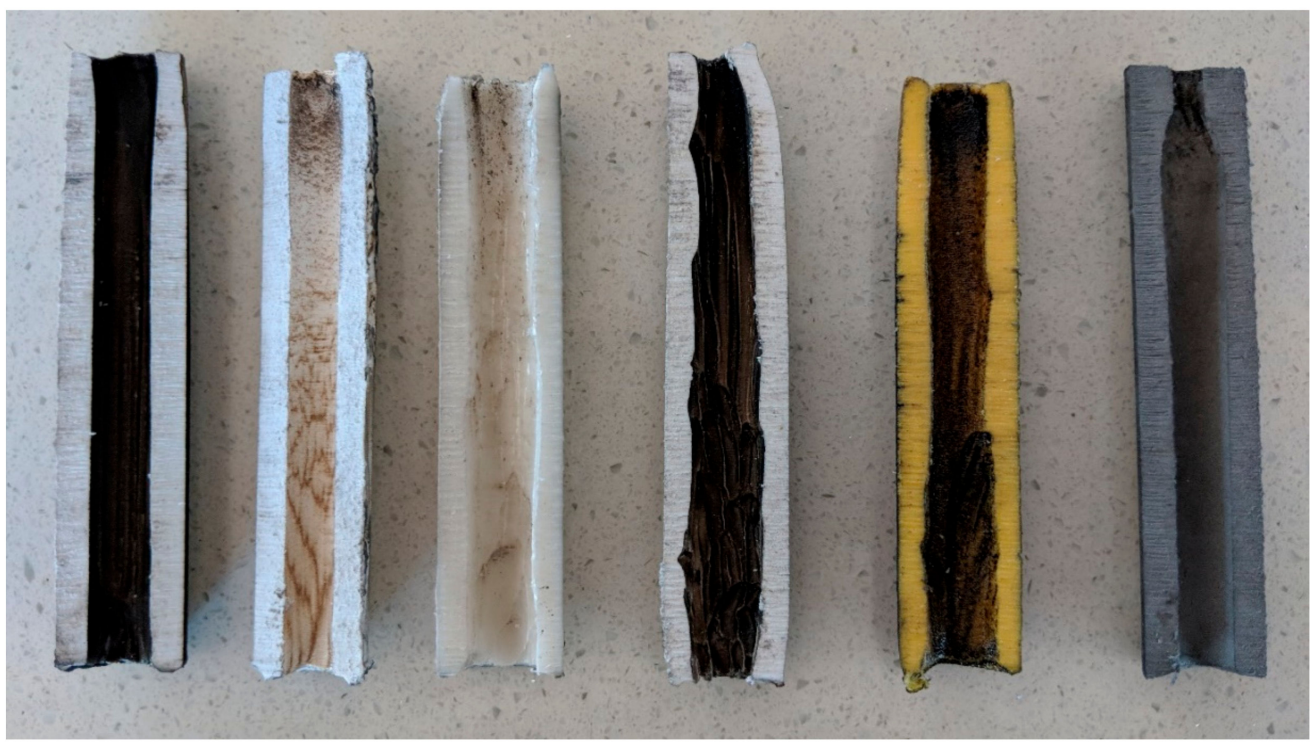

Figure 5. Cross section of each different small-scale fuel grain, left to right: ABS, PLA, PP, ASA, PTEG, and AL.

\section{Conclusions}

This research explored the viability of using commercially available 3D printing filament materials in the manufacture of hybrid rocket fuel grains. Preliminary research has demonstrated the suitability of ABS for use in mid-sized sounding rockets, and this study aimed to build on this by conducting a small-scale testing regime to determine the suitability of seven different commonly available 3D printing materials: ABS, PLA, ASA, PETG, PP, Nylon, and AL (PLA with aluminum particles). In this study, the ASA and Nylon fuel grains showed the highest regression rates, while PETG regression rates were relatively poor. PLA and AL fuel grains showed similar regression rates, showing that the aluminum particles had no contribution to the regression rates measured. It was speculated that the poor performance of the AL fuel grain was largely due to the size, shape and surface area of aluminum particles. Despite this poor performance in this research, the impact of Al particles on fuel grains performance should be analyzed, especially the contribution of different variables, such as, size, shape, and surface area of aluminum particles. The experiment design of this study was very simple as the main objective was to select the FDM materials for a large-scale test, and it has to be considered as a first step toward the realization of the larger scale engine firing campaign.

Author Contributions: M.M. and E.A. conceived the presented research idea and designed of experiments. M.M. carried out and analyzed experiments under E.A. supervision. All authors contributed to the final manuscript.

Funding: This research received no-external funding.

Conflicts of Interest: The authors declare no conflicts of interest.

\section{Nomenclature}

ABS acrylonitrile butadiene styrene

AL PLA with aluminum particles

ASA acrylonitrile styrene acrylate

CNC computer numerically controlled

FDM fused deposition manufacturing

HRM Hybrid Rocket Motor

HTPB Hydroxyl-terminated polybutadiene

PETG Polyethylene terephthalate glycol

PLA polylactic acid

PP polypropylene 
$L \quad$ length of the fuel combustion port

$\mathrm{O} / \mathrm{F} \quad$ oxidizer to fuel ratio

$A_{\text {port }} \quad$ the area of the combustion port

$\dot{m}_{\text {fuel }} \quad$ mass flow rate of fuel

$\dot{m}_{o x} \quad$ mass flow rate of the oxidizer

$\dot{m}_{\text {total }} \quad$ total mass flow rate through the combustion port

$\rho_{\text {fuel }} \quad$ density of fuel

$\overline{\dot{r}} \quad$ fuel regression rate

$r_{0} \quad$ initial fuel port radius

$\bar{r}_{\text {port }} \quad$ mean fuel combustion chamber radius

$t_{b} \quad$ burning time

$\Delta M \quad$ solid-fuel mass loss

\section{References}

1. Krishnan, S. Hybrid rocket technology: An overview. In Proceedings of the 3rd International High Energy Materials Conference and Exhibit, Thiruvanthapuram, India, 6-8 December 2000.

2. Wright, P.K. 21st Century Manufacturing; Prentice Hall: Upper Saddle River, NJ, USA, 2001; Volume 1.

3. Ngo, T.D.; Kashani, A.; Imbalzano, G.; Nguyen, K.T.; Hui, D. Additive manufacturing (3D printing): A review of materials, methods, applications and challenges. Compos. B Eng. 2018, 143, 172-196. [CrossRef]

4. Wang, X.; Jiang, M.; Zhou, Z.; Gou, J.; Hui, D. 3D printing of polymer matrix composites: A review and prospective. Compos. B Eng. 2017, 110, 442-458. [CrossRef]

5. Technologies, G.S. Launch Vehicles. Available online: https://www.gspacetech.com/launch-vehicles (accessed on 11 January 2019).

6. Gu, Q.; Tomaskovic-Crook, E.; Wallace, G.G.; Crook, J.M. 3D bioprinting human induced pluripotent stem cell constructs for in situ cell proliferation and successive multilineage differentiation. Adv. Healthc. Mater. 2017, 6, 1700175. [CrossRef] [PubMed]

7. Tofail, S.A.; Koumoulos, E.P.; Bandyopadhyay, A.; Bose, S.; O’Donoghue, L.; Charitidis, C. Additive manufacturing: Scientific and technological challenges, market uptake and opportunities. Mater. Today 2018, 21, 22-37. [CrossRef]

8. Gibson, M.A.; Mykulowycz, N.M.; Shim, J.; Fontana, R.; Schmitt, P.; Roberts, A.; Myerberg, J.S. 3D printing metals like thermoplastics: Fused filament fabrication of metallic glasses. Mater. Today 2018, 21, 697-702. [CrossRef]

9. Whitmore, S.A.; Peterson, Z.W.; Eilers, S.D. Comparing Hydroxyl Terminated Polybutadiene and Acrylonitrile Butadiene Styrene as Hybrid Rocket Fuels. J. Propuls. Power 2013, 29, 582-592. [CrossRef]

10. Creech, M.; Crandell, A.; Eisenhauer, N.; Marx, S.; Busari, T.; Link, A.; Pourpoint, T.L. 3D Printer for Paraffin Based Hybrid Rocket Fuel Grains. In Proceedings of the 53rd AIAA Aerospace Sciences Meeting, Kissimmee, FL, USA, 5-9 January 2015.

11. Lyne, J.E.; Brigham, A.; Savery, R.; Karcher, K.; Pyron, J.; Adams, L.; Melendez, L. The Use of a 3-D Printed, Polymer Matrix Containing Pulverized Fuel in a Hybrid Rocket. In Proceedings of the 2018 Joint Propulsion Conference, Cincinnati, OH, USA, 9-11 July 2018.

12. Whitmore, S.A. Advantages of Using Additive Manufacturing to Build “Green" Fuels for Hybrid Propulsion. Int. J. Astronaut. Aeronaut. Eng. 2017, 2, 1-12. [CrossRef]

13. Whitmore, S.A. Three-Dimensional Printing of "Green" Fuels for Low-Cost Small Spacecraft Propulsion Systems. J. Spacecr. Rocket. 2017, 55, 13-26. [CrossRef]

14. Spurrier, Z.S. Throttleable GOX/ABS Launch Assist Hybrid Rocket Motor for Small Scale Air Launch Platform. Ph.D. Thesis, Utah State University, Logan, UT, USA, 2016.

15. Walker, S.D. High regression rate hybrid rocket fuel grains with helical port structures. In Proceedings of the 50th AIAA/ASME/SAE/ASEE Joint Propulsion Conference, Cleveland, OH, USA, 28-30 July 2014.

16. Whitmore, S.A.; Sobbi, M.; Walker, S. High Regression Rate Hybrid Rocket Fuel Grains with Helical Port Structures. J. Propuls. Power 2015, 31, 1727-1738. [CrossRef]

17. Walker, S.A.; Walker, S.D. Engineering model for hybrid fuel regression rate amplification using helical ports. J. Propuls. Power 2017, 33, 398-407. 
18. Lips, H. Metal combustion in high performance hybrid rocket propulsion systems. In Proceedings of the 12th Propulsion Conference, Palo Alto, CA, USA, 26-29 July 1976.

19. King, M.K. Aluminum combustion in a solid rocket motor environment. Proc. Combust. Inst. 2009, 32, 2107-2114. [CrossRef]

20. Farbar, E.; Louwers, J.; Kaya, T. Investigation of metallized and nonmetallized hydroxyl terminated polybutadiene/hydrogen peroxide hybrid rockets. J. Propuls. Power 2007, 23, 476-486. [CrossRef]

21. Thomas, J.C.; Petersen, E.L.; Desain, J.D.; Brady, B. Hybrid Rocket Enhancement by Micro-and Nano-Scale Additives in HTPB Fuel Grains. In Proceedings of the 51st AIAA/SAE/ASEE Joint Propulsion Conference, Orlando, FL, USA, 27-29 July 2015.

22. Chiaverini, M.J.; Kuo, K.K.; Peretz, A.; Harting, G.C. Regression-rate and heat-transfer correlations for hybrid rocket combustion. J. Propuls. Power 2001, 17, 99-110. [CrossRef]

23. Kuo, K.K.; Risha, G.A.; Evans, B.J.; Boyer, E. Metals, Energetic Additives, and Special Binders Used in Solid Fuels for Hybrid Rockets. In Fundamentals of Hybrid Rocket Combustion and Propulsion; American Institute of Aeronautics and Astronautics, Inc.: Reston, VA, USA, 2007.

24. Carmicino, C.; Russo Sorge, A. Experimental investigation into the effect of solid-fuel additives on hybrid rocket performance. J. Propuls. Power 2014, 31, 699-713. [CrossRef]

25. Lips, H.R. Heterogeneous combustion of highly aluminized hybrid fuels. AIAA J. 1977, 15, 777-778. [CrossRef]

26. Sun, X.; Tian, H.; Yu, N.; Cai, G. Regression rate and combustion performance investigation of aluminum metallized HTPB/98HP hybrid rocket motor with numerical simulation. Aerosp. Sci. Technol. 2015, 42, 287-296. [CrossRef]

27. Prospector, U. Plastics. Available online: https://plastics.ulprospector.com (accessed on 11 May 2019).

28. Veale, K.; Adali, S.; Pitot, J.; Brooks, M. A review of the performance and structural considerations of paraffin wax hybrid rocket fuels with additives. Acta Astronaut. 2017, 141, 196-208. [CrossRef]

(C) 2019 by the authors. Licensee MDPI, Basel, Switzerland. This article is an open access article distributed under the terms and conditions of the Creative Commons Attribution (CC BY) license (http://creativecommons.org/licenses/by/4.0/). 